\title{
Diversity of Symbiodinium dinoflagellate symbionts from the Indo-Pacific sea slug Pteraeolidia ianthina (Gastropoda: Mollusca)
}

\author{
William K. W. Loh $^{1, *}$, Melissa Cowlishaw ${ }^{1,2}$, Nerida G. Wilson ${ }^{1,3}$ \\ ${ }^{1}$ Centre for Marine Studies, University of Queensland, St Lucia, Queensland 4072, Australia \\ ${ }^{2}$ Present address: School of Marine Biology and Aquaculture, James Cook University, Townsville, Queensland 4811, Australia \\ ${ }^{3}$ Present address: Department of Biological Sciences, 101 Rouse Life Sciences Building, Auburn University, Auburn, \\ Alabama 36849, USA
}

\begin{abstract}
The aeolid nudibranch Pteraeolidia ianthina hosts symbiotic dinoflagellates in the same way as many reef-building corals. This widespread Indo-Pacific sea slug ranges from tropical to temperate waters, and offers a unique opportunity to examine a symbiosis that occurs over a large latitudinal gradient. We used partial 28S and 18S nuclear ribosomal (nr) DNA to examine the genetic diversity of the Symbiodinium dinoflagellates contained within $P$. ianthina. We detected Symbiodinium from genetic clades A, B, C and D. P. ianthina from tropical regions (Singapore, Sulawesi) host Symbiodinium clade C or D or both; those from the subtropical eastern Australian coast (Heron Island, Mon Repo, Moreton Bay, Tweed Heads) host Symbiodinium clade C, but those from the temperate southeastern Australian coastline (Port Stephens, Bare Island) host clade A or B or both. The Symbiodinium populations within 1 individual nudibranch could be homogeneous or heterogeneous at inter- or intra-clade levels (or both). Our results suggested that the Pteraeolidia-Symbiodinium symbiosis is flexible and favours symbiont phylotypes best adapted for that environment. This flexibility probably reflects the function of the symbiont clade in relation to the changing environments experienced along the latitudinal range, and facilitates the large geographic range of $P$. ianthina.
\end{abstract}

KEY WORDS: Symbiosis · Zooxanthellae · Nudibranchia · Molecular diversity · Biogeography Resale or republication not permitted without written consent of the publisher

\section{INTRODUCTION}

A widening group of marine invertebrate taxa (Mollusca, Foraminifera, Platyhelminthes, Cnidaria, Porifera and Urochordata) are now known to harbour endosymbiotic dinoflagellates of the genus Symbiodinium (Trench 1997). Among the molluscs, the aeolid nudibranch Pteraeolidia ianthina (Angas, 1864) is a widespread host to Symbiodinium, and is found in both temperate and tropical regions of the Indian and Pacific Oceans (Rudman 1982, King \& Fraser 2002). Rudman (1982) reported its endosymbiosis with Symbiodinium in a period when all symbiotic dinoflagellates were considered a single species, Symbiodinium microadriaticum (Kawaguti, 1944).
The Symbiodinium occurring in Pteraeolidia ianthina are viable, and they respire, photosynthesize and multiply in situ (Hoegh-Guldberg \& Hinde 1986, Waegele \& Johnsen 2001). The nudibranch receives up to $50 \%$ of the total carbon photosynthetically-fixed by each Symbiodinium cell via translocation (HoeghGuldberg \& Hinde 1986). Studies by Kempf (1984) show that starved $P$. ianthina kept in constant light lost weight more slowly than those in the dark. The nudibranchs maintained in the laboratory with light but without additional food sources survived for up to 192 d (Kempf 1984). P. ianthina clearly gain substantial nutrition from their symbionts, and can sustain themselves solely on symbiont phototrophy for long periods. The symbiont population in $P$. ianthina increased when 
maintained in the high light conditions of a laboratory (Hoegh-Guldberg \& Hinde 1986), indicating a symbiosis that is re-adjusted according to ambient environmental parameters.

Pteraeolidia ianthina presumably acquire Symbiodinium through horizontal transmission, as symbionts have never been observed within fertilized eggs or in the lecithotrophic larvae (Kempf 1984). The acquisition of Symbiodinium by $P$. ianthina might occur directly from the water column, as demonstrated in cnidarians (Lewis \& Coffroth 2004). Alternatively, symbiont acquisition might be via ingestion of prey that also harbour these symbionts (Kempf 1984). Prey ingestion has been a route of symbiont entry in other nudibranch species such as Aeolidia papillosa, Berghia verrucicornis and Phyllodesmium spp. (Kempf 1991, Rudman 1991, McFarland \& Muller-Parker 1993).

Although this dinoflagellate was initially thought to be a single species, molecular methods have revealed the existence of several phylotypes in Symbiodinium (up to 8 genetically diagnosable clades: A, B, C, D, E, F, G and H (Baker 2003, Pochon et al. 2004). Presently, only a few Symbiodinium species have been fully described morphologically (Trench 1997), and the original name of $S$. microadriaticum is assigned to the symbiont of the jellyfish Cassiopea xamachana (Trench 1997). Many hosts will accommodate only a single phylotype of Symbiodinium (Baker \& Rowan 1997), but this 'specificity' concept is often confused with the symbionts' ability to also utilize different hosts. Heterogeneous populations of Symbiodinium types from the same clade or different clades exist in a number of coral species (Rowan \& Knowlton 1995, Rowan et al. 1997, Loh et al. 2001). Different types of Symbiodinium present in a single host or host range can be used to infer symbiotic mechanisms adapted to the prevailing environmental conditions (Buddemeier \& Fautin 1993, Rowan et al. 1997), as different types can support dissimilar growth rates under identical conditions (Little et al. 2004). Some corals and anemones host a range of symbionts over different latitudinal and climatic zones (Loh et al. 2001, Rodriguez-Lanetty et al. 2001, Toller et al. 2001) or depths (Rowan et al. 1997, Iglesias-Preito et al. 2004). These examples are likely to reflect the selection of symbionts physiologically optimized for photosynthesis in different environments.

Despite the widespread nature of Pteraeolidia ianthina, the genetic diversity of its symbionts has not been evaluated extensively. To date, one study reported that a single specimen of $P$. ianthina from Hayama Bay (Japan) hosted both Symbiodinium spp. clade A and D (Ishikura et al. 2004). An additional specimen from the Great Barrier Reef (Australia) contained clade C (La Jeunesse et al. 2004). In the present study, the dinoflagellate symbionts of $P$. ianthina were sampled along a tropical to temperate clinefrom Singapore to Sulawesi (Indonesia) and down the eastern coast of Australia. This latitudinal sampling represents the central part of the widespread IndoPacific range of this nudibranch. We examined the genetic identity of Symbiodinium phylotypes from $P$. ianthina and, thus, the limits of specificity of the host-symbiont relationship.

\section{MATERIALS AND METHODS}

Collection and DNA extraction. A total of 19 Pteraeolidia ianthina individuals were collected from sites off Singapore, Indonesia, and the eastern coast of Australia (see Table $1 \&$ Fig. 1 for details). Animals were collected from depths ranging from the intertidal zone to $30 \mathrm{~m}$ (Table 1). The nudibranchs were anaesthetized by chilling, and placed in $95 \%$ ethanol for preservation. The samples were stored at $-70^{\circ} \mathrm{C}$ until extracted for DNA.

All tissue samples were washed 3 times and suspended in $500 \mu \mathrm{l}$ of DNA buffer (Rowan et al. 1997). The samples were macerated into slurry and incubated with $1 \%$ sodium dodecyl sulphate (SDS) at $65^{\circ} \mathrm{C}$ for $1 \mathrm{~h}$. The samples were incubated a further $12 \mathrm{~h}$ at $37^{\circ} \mathrm{C}$ with proteinase $\mathrm{K}\left(0.5 \mu \mathrm{g} \mathrm{ll}^{-1}\right)$. Total DNA was extracted using the phenol-chloroform method as in Loh et al. (2001).

PCR amplification. The variable domains D1 and D2 of Symbiodinium large subunit (28S nuclear ribosomal [nr] DNA) was amplified with the protocol used previously by Loh et al. (2001). The small subunit (18S nuclear ribosomal [nr] DNA) gene of Symbiodinium spp. was amplified with the universal primers

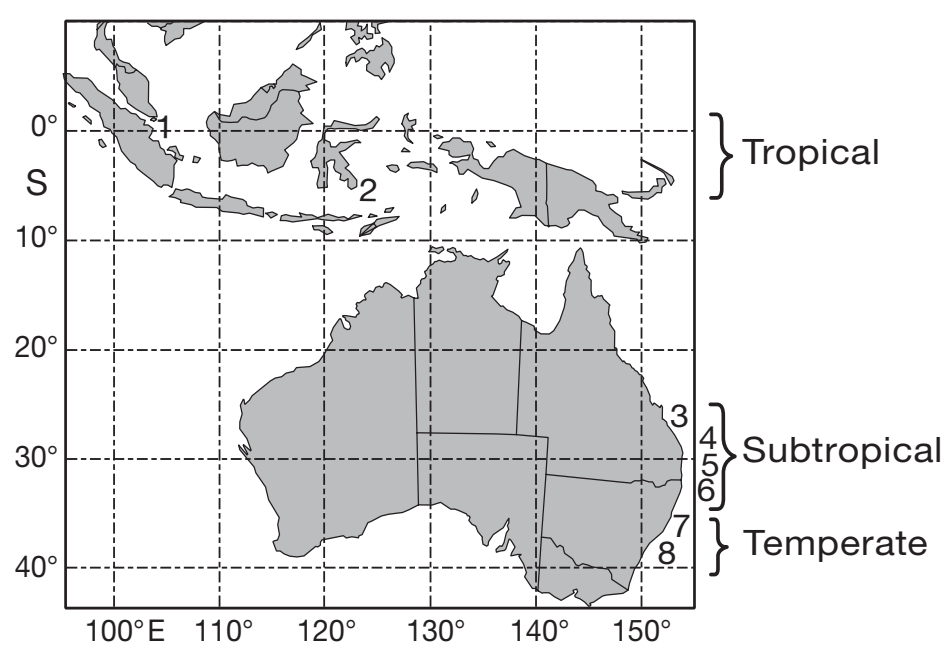

Fig. 1. Sampling sites and respective climatic zones. 1: Singapore; 2: Sulawesi; 3: Heron Island; 4: Mon Repo; 5: Moreton Bay; 6: Tweed Heads; 7: Port Stephens; 8: Bare Island 
Table 1. Symbiodinium spp. from Pteraeolidia ianthina. Location, depth and phylotypes. * Sequences obtained from cloned DNA

\begin{tabular}{|c|c|c|c|c|}
\hline \multirow{2}{*}{$\begin{array}{l}\text { Site and } \\
\text { P. ianthina } \\
\text { (Pi) hosts }\end{array}$} & \multirow[t]{2}{*}{$\begin{array}{l}\text { Latitude/ } \\
\text { Longitude }\end{array}$} & \multirow[t]{2}{*}{$\begin{array}{l}\text { Depth } \\
\text { (m) }\end{array}$} & \multicolumn{2}{|c|}{$\begin{array}{c}\text { Symbiodinium clade } \\
\text { (accession code) }\end{array}$} \\
\hline & & & $18 \mathrm{~S}$ & $28 \mathrm{~S}$ \\
\hline Singapore & $1^{\circ} 17^{\prime} \mathrm{S}$ & 10 & & \\
\hline Singapore Pi 1 & $103^{\circ} 48^{\prime} \mathrm{E}$ & & $\mathrm{C}^{*}(\mathrm{AY} 903341)$ & D* (AY903333) \\
\hline Singapore Pi 2 & & & $\mathrm{C}^{*}$ (AY903342) & \\
\hline Singapore Pi 3 & & & $\mathrm{D}^{*}(\mathrm{AY} 903340)$ & \\
\hline Singapore Pi 4 & & & & $\mathrm{D}^{*}(\mathrm{DQ} 286774)$ \\
\hline SE Sulawesi & $2^{\circ} 13^{\prime} \mathrm{S}$ & 6 & & \\
\hline Sulawesi Pi 1 & $120^{\circ} 10^{\prime} \mathrm{E}$ & & D (AY903343) & D (AY903339) \\
\hline Sulawesi Pi 2 & & & & C (AY903328) \\
\hline Heron Island & $23^{\circ} 50^{\prime} \mathrm{S}$ & 12 & & \\
\hline Heron Island Pi 1 & $151^{\circ} 90^{\prime} \mathrm{E}$ & & & C (AY903327) \\
\hline Mon Repo & $24^{\circ} 80^{\prime} \mathrm{S}$ & 0 & & \\
\hline Mon Repo Pi 1 & $152^{\circ} 50^{\prime} \mathrm{E}$ & & $\mathrm{C}(\mathrm{DQ} 227700)$ & C (AY903329) \\
\hline Moreton Bay & $27^{\circ} 23^{\prime} \mathrm{S}$ & 20 & & \\
\hline Moreton Bay Pi 1 & $153^{\circ} 33^{\prime} \mathrm{E}$ & & & C (AY903326) \\
\hline Tweed Heads & $28^{\circ} 00^{\prime} \mathrm{S}$ & 29 & & \\
\hline Tweed Heads Pi 1 & $153^{\circ} 38^{\prime} \mathrm{E}$ & & C (AY903346) & C (AY903338) \\
\hline Port Stephens & $32^{\circ} 26^{\prime} \mathrm{S}$ & 9 & & \\
\hline Port Stephens Pi 1 & $152^{\circ} 32^{\prime} \mathrm{E}$ & & & B (AY903331) \\
\hline Port Stephens Pi 2 & & & & B (AY903332) \\
\hline Bare Island & $33^{\circ} 59^{\prime} \mathrm{S}$ & 8 & & \\
\hline Bare Island Pi 1 & $151^{\circ} 14^{\prime} \mathrm{E}$ & & $\mathrm{B}^{*}(\mathrm{AY} 903344)$ & \\
\hline Bare Island Pi 2 & & & $\mathrm{~B}^{*}(\mathrm{AY} 903345)$ & \\
\hline Bare Island Pi 3 & & & & $\mathrm{~A}^{*}$ (clone 1 AY903335) \\
\hline & & & & $\mathrm{A}^{*}$ (clone 2 DQ227701) \\
\hline & & & & B* (clone 3 AY903334) \\
\hline Bare Island Pi 4 & & & & $\mathrm{~A}^{*}(\mathrm{AY} 903336)$ \\
\hline Bare Island Pi 5 & & & & $\mathrm{~A}^{*}$ (clone 1 AY903337) \\
\hline & & & & $\mathrm{A}^{*}$ (clone $\left.2 \mathrm{DQ} 227702\right)$ \\
\hline Bare Island Pi 6 & & & $\mathrm{~B}^{*}$ (DQ227698) & \\
\hline Bare Island Pi 7 & & & $\mathrm{~B}^{*}$ (DQ227699) & $\mathrm{B}^{*}(\mathrm{AY} 903330)$ \\
\hline Japan & $35^{\circ} \mathrm{N}$ & $?$ & & \\
\hline (Ishikura et al. 2004) & 4) $139^{\circ} \mathrm{E}$ & & & \\
\hline Japan Pi 1 & & & D (AB085914) & \\
\hline
\end{tabular}

facturer's instructions. The plasmids were transformed into competent Escherichia coli cells (TOPO, Invitrogen). Selected transformants were picked from plates and directly PCR amplified following the aforementioned PCR protocols. PCR amplifications of the clones were purified using GFX columns (Amersham Biosciences). DNA sequences were determined in both directions using the dye terminator automatic sequencing facility at the Australian Genome Research Facility at the University of Queensland. Symbiodinium sequences from different hosts required similarity of $99 \%$ or above to be considered identical.

Single stranded conformational polymorphism analysis. Single Stranded Conformational Polymorphism (SSCP) analysis was performed using $20 \mu \mathrm{l}$ of PCR product mixed with an equal volume of loading buffer (95\% formamide $10 \mathrm{mM} \mathrm{NaOH}, 0.25 \%$ bromophenol blue and $0.25 \%$ xylene cyanol) to denature for $5 \mathrm{~min}$ at $95^{\circ} \mathrm{C}$. After denaturing, the mixed aliquots were immediately chilled on crushed ice and run on a polyacrylamide MDE gel (FMC Bioproducts) in $0.6 \times \mathrm{TBE}$ at $160 \mathrm{~V}$ for $13 \mathrm{~h}$ at room temperature. The SSCP patterns were stained with ethidium bromide and visualized with UV transillumination.

Alignment and phylogenetic analyses. Sequences were aligned using CLUSTAL W (Thompson et al. 1994) applying a gap penalty of 10 and an exten-

18A1 5'-CCTACTCTGGTTGATCCTGCCACT-3' (forward) and 1800 5'-TAATGATCCTTCCGCAGG TT-3' (reverse) (modified for nudibranchs by WollscheidLengeling et al. 2001). For $18 \mathrm{~S}$ the following PCR protocol was used: 38 cycles at $94^{\circ} \mathrm{C}$ for $30 \mathrm{~s}, 52.5^{\circ} \mathrm{C}$ for $50 \mathrm{~s}, 72^{\circ} \mathrm{C}$ for $2 \mathrm{~min} 30 \mathrm{~s}$. The reactions were screened for nudibranch or Symbiodinium 18S nuclear ribosomal (nr) DNA by cloning and sequencing. Only Symbiodinium data is presented in this study.

Cloning and sequencing. All PCR products were initially sequenced without cloning. The ability to obtain unambiguous sequences directly from PCR products was interpreted as indicating that the symbiont populations were predominantly of one phylotype. If ambiguous sequences were initially obtained, these PCR products were subsequently cloned and resubmitted for sequencing. In these instances, PCR amplifications were ligated into PGEM-T vectors (Promega) according to the manu- sion penalty of 0.05 , and the alignment was also edited by eye. The alignments were deposited in Treebase (www.treebase.org). We follow the clade systematics reviewed by Baker (2003), where many sequences currently denoted clade E in GenBank (www.ncbi.nlm.nih. gov; sequences marked with * below) should be designated to clade D. Clade E has been assigned to Symbiodinium californium from the temperate anemone Anthopleura spp. (Baker 2003). The reference symbiont sequences included here are clade A (accession numbers M88521, AB016573, AB016538, U63480, U63483 AF427455), clade B (U20959, AF238257, AF427447, U63484, AF427460, AF060891), clade C (U20957, AF238258, AF427453, U63481, U63485, AJ621128), clade D (AF238261*, AF238262*, AF231263*, AF170149, AF139197, AF396626, AY074951), and clade E (Symbiodinium californium AF225965). SSU and LSU trees were rooted using Gymnodinium beii 
(accession nos. U41087 and AF060900 respectively) because previous phylogenetic analyses have shown that this genus typically shows a sister group relationship to the Symbiodinium spp. clade (Wilcox 1998).

Trees were constructed using maximum parsimony (MP), maximum likelihood (ML) and Bayesian methods. Prior to these analyses, Modeltest version 2.06 (Posada \& Crandall 1998) was used to determine the most appropriate substitution model for the data for the ML and Bayesian analyses. Using the hierarchical likelihood ratio tests, these were found to be the $\mathrm{TrNef}+\mathrm{G}$ for Pteraeolidia-Symbiodinium18S nuclear ribosomal (nr) DNA and 28S nuclear ribosomal (nr) DNA. Although identical models of evolution were obtained for each gene using the model substitution analysis, a combined analysis using both genes was not possible owing to the differential PCR success of various individuals and clones.

MP and ML analyses were conducted using the PAUP beta version 4.0b10 (Swofford 2002). All characters were given equal weight and were unordered. The MP analysis was carried out by the heuristic search method, with 100 random additions of taxa, each followed by Tree Bisection-reconnection (TBR) branch-swapping. Starting-trees were obtained by stepwise-addition using simple addition sequence. MP clades were assessed with 1000 bootstrap replicates (excluding uninformative characters), with 100 random additions of taxa for each replicate. For ML, the heuristic searches were again carried out with 100 random additions of taxa, followed by TBR branch-swapping. ML clade support was assessed with 100 bootstrap replicates (1000 in the combined host $28 \mathrm{~S})$, using the same model as the heuristic searches.

The Bayesian analyses were implemented in MrBayes (Ronquist \& Huelsenbeck 2003) and were based on the models selected by Modeltest above. Starting from random trees, 4 Markov chains (with 3 heated chains) were run simultaneously to sample trees using the Markov Chain Monte Carlo (MCMC) principle. After the burn-in phase (the first 3300 and 3600 generations, respectively, for $18 \mathrm{~S}$ and $28 \mathrm{~S}$ analyses were discarded), every 100th tree out of $10^{6}$ was considered. The phylogenetic trees generated in all analyses were visualized using TREEVIEW version 1.6.5 (Page 1996).

\section{RESULTS}

Partial 18S and 28S nuclear ribosomal (nr) DNA gene sequences obtained from Pteraeolidia ianthina are listed in Table 1. The 18S alignment resulted in 496 positions, 44 of which were parsimony-informative. Symbiodinium spp. phylotypes recovered with $18 \mathrm{~S}$ data are listed in Table 1. These were clade B (Bare Island Pteraeolidia ianthina [Pi] 1, 2, 6 and 7); C (Singapore Pi 1, 2; Mon Repo Pi 1; Tweed Heads Pi 1); D (Singapore Pi 3, Sulawesi Pi 1, Japan Pi 1). Symbiodinium from another nudibranch species, Phyllodesmium briareum (DNA sequence from Waegele et al. 2003) clustered with clade D. MP analysis recovered 1000 equally parsimonious trees, while ML returned 6. The consensus Bayesian tree did not differ in topology, and showed the well-supported clades B + $\mathrm{C}$ and $\mathrm{D}$ to be reciprocally monophyletic (sister taxa). Clade A was the sister clade to B + C + D + E. As the tree topology was similar in all analyses, bootstrap values are shown on 1 of the ML trees (Fig. 2).

The 28S alignment resulted in 678 positions, 225 of which were parsimony-informative. The Symbiodinium spp. phylotypes recovered with 28S data are listed in Table 1. These were clade A phylotypes (Bare Island Pi 3, 5), clade B (Bare Island Pi 3, 7; Port Stephens Pi 1, 2), clade C (Tweed Heads Pi 1; Moreton Bay Pi 1; Mon Repo Pi 1; Heron Island Pi 1; Sulawesi Pi 2), and clade D (Singapore Pi 1, 4; Sulawesi Pi 1). MP analysis resulted in 1000 equally parsimonious trees,

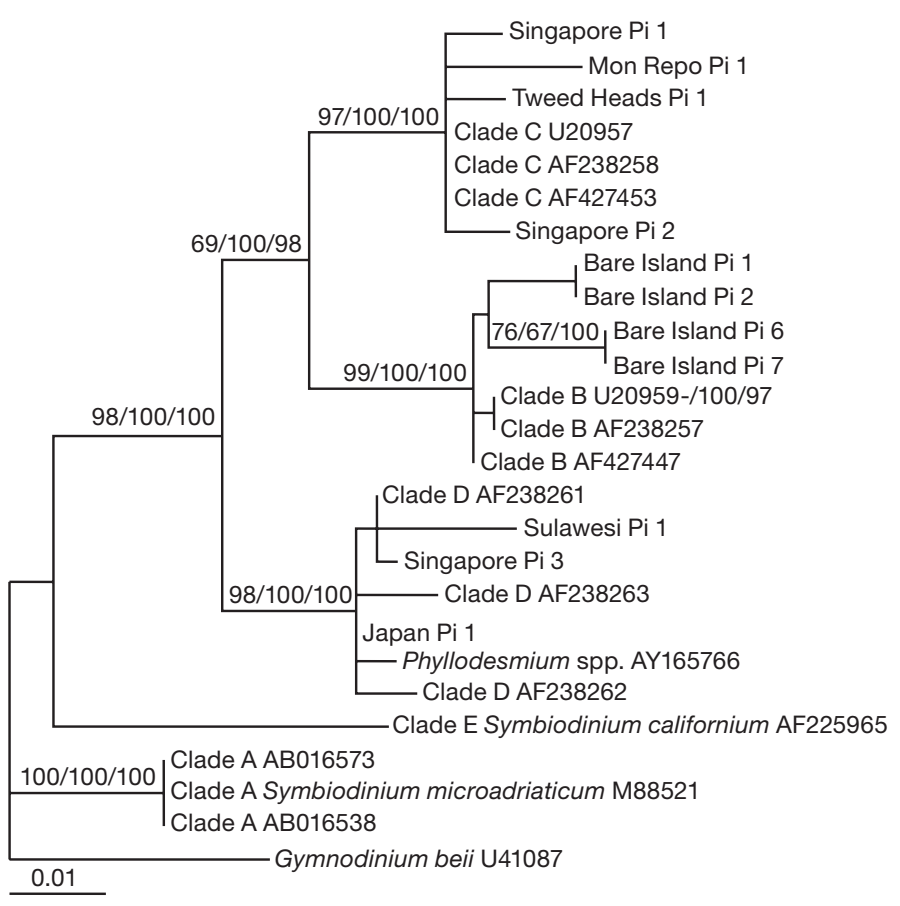

Fig. 2. Symbiodinium spp. 18S nuclear ribosomal (nr) DNA maximum likelihood tree of Symbiodinium types (marked 'Pi') harboured by Pteraeolidia ianthina. Numbers at nodes indicate percentage of 1000/1000/1000 bootstrap replications or posterior probabilities supporting each node (maximum likelihood/maximum parsimony/Bayesian). Unless indicated, only bootstrap values $>95 \%$ are shown. Accession numbers of Gymnodinium beii (outgroup), Symbiodinium from clade A, B, C, D, and E, and from the nudibranch Phyllodesmium sp. are listed 
and $2 \mathrm{ML}$ trees were recovered. The consensus Bayesian tree showed the same topology as the other methodologies. Again, the well-supported clades B + C were recovered as the most closely derived sister taxa, and clade D was the sister to these. Clade A formed themost basal clade. Those branches from clade A formed a distinct subclade from the reference clade sequences. As the tree topology was similar in all analyses, bootstrap values are shown on the ML tree (Fig. 3). 28S sequence data for Symbiodinium californium clade E was not available for analysis at the time of writing.

Both 28S and 18S analyses produced trees with the clades of Symbiodinium from Pteraeolidia ianthina correlating to broad geographic regions. P. ianthina from Singapore and Sulawesi are host to Symbiodinium clade $\mathrm{C}$ or $\mathrm{D}$, those off eastern Australia are host to Symbiodinium clade C, and those off southeastern Australia are host to Symbiodinium clade A or B. There did not appear to be a correlation of Symbiodinium clades with the collection depth of the host, as clade $\mathrm{C}$ was found in nudibranchs collected at 0, 20 and $29 \mathrm{~m}$. The motility of these nudi-

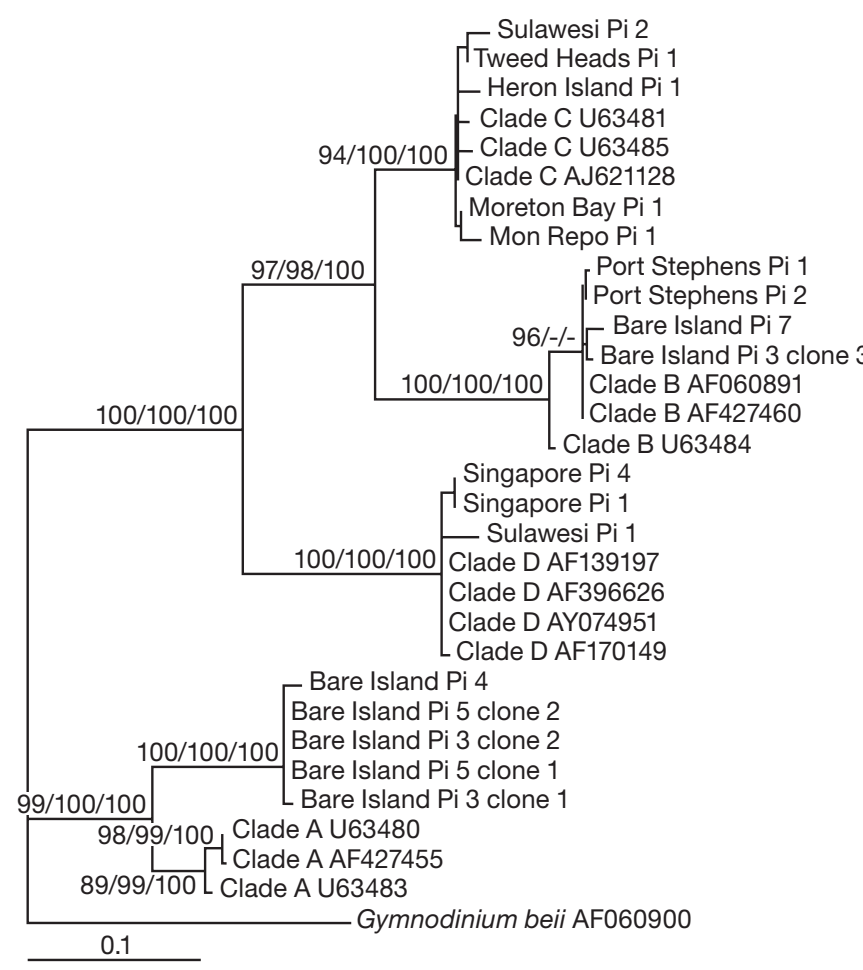

Fig. 3. Symbiodinium spp. 28S nuclear ribosomal (nr) DNA maximum likelihood tree of Symbiodinium types (marked ' $\mathrm{Pi}$ ') harboured by Pteraeolidia ianthina. Numbers at nodes indicate percentage of 100/1000/1000 bootstrap replications or posterior probabilities supporting each node (maximum likelihood/maximum parsimony/Bayesian). Unless indicated, only bootstrap values $>95 \%$ are shown. Accession numbers for clade A, B, C, D and Gymnodinium beii (outgroup) are listed branchs probably rules out the development of a depth-Symbiodinium clade relationship.

Unambiguous sequences (interpreted here as indicating a predominately homogenous Symbiodinium population) were obtained from Pteraeolidia ianthina individuals from Moreton Bay, Mon Repo, Heron Island, Port Stephens, Tweed Heads and Sulawesi. In contrast, ambiguous sequences were obtained from some $P$. ianthina individuals from Singapore and Bare Island, indicating that they contained heterogenous populations. Representative SSCP analysis of 28S PCR products of Pteraeolidia-Symbiodinium from Bare Island ( $>2$ bands) and Moreton Bay ( 2 bands) shows the expected genetic profile of a heterogeneous and homogeneous population of Symbiodinium, respectively (Fig. 4). The cloning and sequencing of $18 \mathrm{~S}$ and 28S RNA genes from all Singapore and Bare Island $P$. ianthina shows that up to 2 clades may be hosted simultaneously (clades C and D from Singapore, and A and B from Bare Island, Table 1).

\section{DISCUSSION}

From our broad survey of high to low latitudinal environments, at least 4 clades of Symbiodinium (A, B, $\mathrm{C}$ and D) were detected in Pteraeolidia ianthina. Symbiodinium clade B had not been previously observed in P. ianthina (Ishikura 2004, LaJeunesse et al. 2004) and other nudibranch-Symbiodinium symbioses (Waegele et al. 2003). Relatively few coral species are known to host up to 4 clades of Symbiodinium over a broad geographical range (Rowan et al. 1997, Toller et al. 2001). $P$. ianthina may also harbour combinations of at least 2 Symbiodinium clades simultaneously.

Using partial 28S nuclear ribosomal (nr) DNA and 18S nuclear ribosomal (nr) DNA genetic sequences, a large degree of latitudinally-based phylogeographic structuring among the Symbiodinium symbionts of Pteraeolidia ianthina becomes evident. Nudibranchs from the temperate waters (off Bare Island and Port Stephens) form associations with several Symbiodinium phylotypes of clade $\mathrm{A}$ or $\mathrm{B}$, or both; those from subtropical regions (off Tweed Heads, Moreton Bay, Mon Repo and Heron Island) associate with clade C phylotypes. $P$. ianthina from tropical regions, such as Singapore and Sulawesi, host Symbiodinium clades C or D, or both. A previous study on the scleractinian coral Plesiastra versipora along the eastern coast of Australia showed a similar break in Symbiodinium distribution: clade B predominated in temperate waters and clade $\mathrm{C}$ in subtropical and tropical regions (Rodriguez-Lanetty et al. 2001). The change in clade distribution in that study occurred somewhere between Sydney (New South Wales, $33^{\circ} \mathrm{S}$ ) and Moreton 


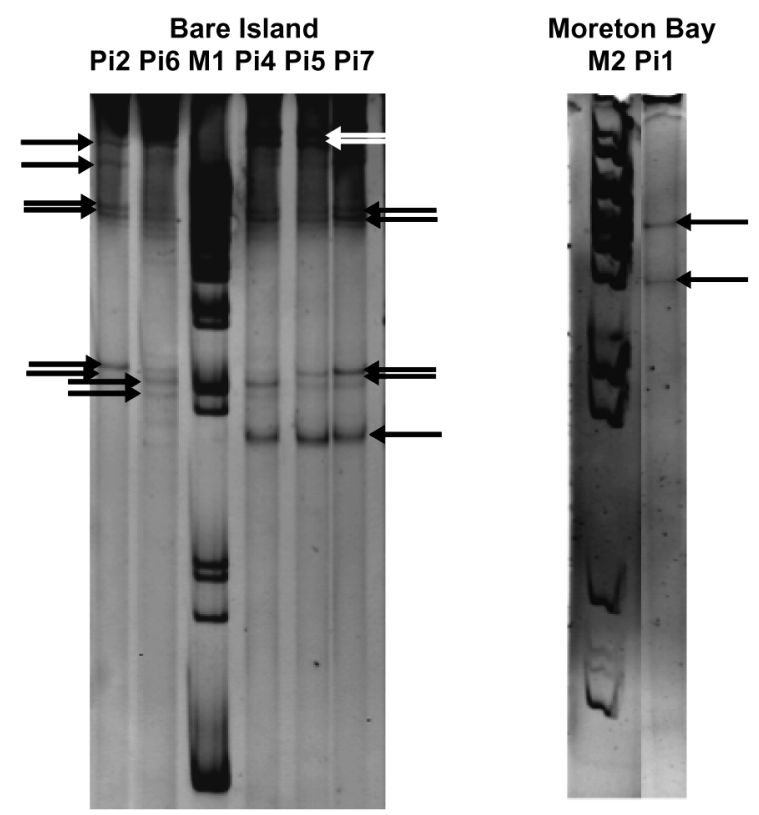

Fig. 4. Symbiodinium spp. Single-stranded conformational polymorphism patterns (arrows) of partial 28S nuclear ribosomal (nr) DNA amplified from Symbiodinium in Pteraeolidia ianthina from Bare Island and Moreton Bay. Profiles were produced from $650 \mathrm{bp}$ fragments following heat denaturation. Marker M1 = $1 \mathrm{~Kb}$ Plus DNA (Invitrogen), M2 = GeneRuler $1 \mathrm{~kb}$ DNA Ladder (Fermentas)

Bay (Queensland, $27^{\circ} \mathrm{S}$ ). Our results indicate that, for $P$. ianthina, the break occurs further south along the New South Wales coast: somewhere between Port Stephens $\left(32^{\circ} \mathrm{S}\right)$ and Tweed Heads $\left(28^{\circ} \mathrm{S}\right)$.

The overall distribution patterns of Symbiodinium in Pteraeolidia ianthina hosts agree with previous studies on other host taxa. Symbiodinium clade $\mathrm{B}$ in the Pacific Ocean has been shown to be more commonly detected in temperate waters (RodriguezLanetty et al. 2001), even though it is common in tropical Caribbean corals (Baker \& Rowan 1997). Clades A, C and D have been previously detected in subtropical to tropical latitudes of the Pacific Ocean but not in temperate waters (Loh et al. 2001, van Oppen et al. 2001). In this study, Symbiodinium phylotypes of clades C and D were found to be common to subtropical and tropical $P$. ianthina. However, our clade A phylotypes were not restricted to tropical waters; instead, they were found only in P. ianthina off temperate Bare Island. This could be an artifact of a low sampling regime, even though the number of nudibranchs sampled from the tropical and temperate regions were similar. Interestingly, our clade A sequences in GenBank show high identity (99 to $100 \%$ ) with Symbiodinium from the temperate Atlantic anemone Anemonia viridis (GenBank accession number AY074940) (BLASTN [basic local align- ment search tool analysis], data not shown). This may suggest a global distribution of this Symbiodinium clade in temperate waters; however, this needs to be investigated with higher resolution markers.

The temperate latitude Pteraeolidia ianthina specimen from Hayama Bay, Japan (Table 1), hosts 2 Symbiodinium clades, and initially appears to be an exception to the generalized geographic distribution of Symbiodinium. The presence of clade A in P. ianthina at this northern temperate latitude is consistent with its presence at Bare Island, at a similar but southern latitude. However, Symbiodinium clade D usually indicates a tropical habitat, and its presence in Hayama Bay is likely to be the result of the Kuroshio Current. This current brings warm tropical water northward past Hayama Bay, and transports many warm water marine organisms to otherwise temperate waters off mainland Japan (Johnson \& Terazaki 2003). The hosting of both clade A and D in this specimen demonstrates an interesting mix of temperate and tropical symbioses.

The observed biogeographical trends of Symbiodinium symbioses may reflect a functional, temperature-based symbiont choice. The possession of a particular phylotype over another can, in theory, provide strong advantages to the survival of the host. For example, studies of corals bearing Symbiodinium clade D in tropical latitudes have been shown to maintain photosynthetic activity under the same heat stresses that cause corals with clade $\mathrm{C}$ to lose photosynthesic ability (Rowan 2004). Tropical corals containing a clade $\mathrm{C}$ phylotype have been shown to have growth rates 2 to 3 times faster than the same host species with a clade D type (Little et al. 2004). Therefore, the establishment of a heat-tolerant and fastgrowing Symbiodinium clade C and D population by Pteraeolidia ianthina in the tropics might be an advantage for a constantly warm and nutrient-poor environment. Nothing is yet known of the physiology of Symbiodinium clade A or B, or why such a prevalence of clade B symbionts exists in temperate Indo-Pacific taxa. As adult coral colonies usually maintain a particular set of symbionts for long periods (Goulet \& Coffroth 2003), it has been suggested that their present-day symbiont community structure is a reflection of the environmental conditions under which the symbioses were initially established (LaJeunesse et al. 2004). Given the short lifespan of most aeolid nudibranchs, it is likely that $P$. ianthina symbioses are a better reflection of symbioses selected for present day conditions.

Unlike the majority of other zooxanthellate invertebrates, Pteraeolidia ianthina are motile animals and are potentially able to manipulate the environment that their symbionts are exposed to. The host's motility may help position an individual in optimal photic 
zones, and a clade-heterogeneous population might adapt better to rapidly changing light levels experienced during movement. As a relatively fast-moving nudibranch, $P$. ianthina would be able to position itself in lighter or more shaded environments, in warmer or cooler temperatures, and also to change the depth of its habitat (dependant on location). Whether such behavioural changes are carried out by individual nudibranchs remains to be experimentally tested.

The results of this study provide an insight into the biogeographic range of Pteraeolidia ianthina and its symbiont populations. $P$. ianthina demonstrates a flexible symbiosis, maintaining non-specific homogeneous or heterogeneous populations of Symbiodinium. The analyses also show a latitudinal gradient distribution, with Symbiodinium clades A and B phylotypes found in temperate waters, clade $\mathrm{C}$ in mid-latitude subtropical waters, and clades $\mathrm{C}$ and $\mathrm{D}$ in low latitude tropical waters. This distribution is consistent with studies that indicate a prevalence of Symbiodinium clades B and C in temperate and tropical waters, respectively (LaJeunesse \& Trench 2000, Rodriguez-Lanetty et al. 2001). Further studies into the efficacy of symbioses from varying latitudinal zones will allow comprehensive hypotheses on the establishment of these biogeographic relationships.

Acknowledgements. We thank those who assisted in specimen collection, in particular M. Stat, A. Nishikawa, D. Harris, P. Fisher, R. Wallace, D. Pagendam, J. Chambers, I. Fellegara, D. Atkinson, L. Atkinson, D. Harasti, D. Jackson and C. Huffard. J. Healy commented on an early version of the manuscript. We thank anonymous reviewers for their constructive suggestions. Collecting permits were kindly issued by the Indonesian Institute of Sciences (LIPI), Great Barrier Reef Marine Park Authority, Department of Primary Industries Queensland, Queensland Environmental Protection Authority/Queensland Parks and Wildlife Service, and New South Wales Fisheries. The study was supported in part by the Australian Research Council, Centre for Marine Studies (University of Queensland), and the Hawaiian Malacological Society.

\section{LITERATURE CITED}

Baker A (2003) Flexibility and specificity in coral-algal symbiosis: diversity, ecology, and biogeography of Symbiodinium. Annu Rev Ecol Evol Syst 34:661-689

Baker A, Rowan R (1997) Diversity of symbiotic dinoflagellates (zooxanthellae) in scleractinian corals of the Caribbean and eastern Pacific. Proc 8th Int Coral Reef Symp 2: 1301-1306

Buddemeier R, Fautin D (1993) Coral bleaching as an adaptive mechanism. BioScience 43:320-326

Goulet TL, Coffroth M (2003) Stability of an octocoral-algal symbiosis over time and space. Mar Ecol Prog Ser 250: $117-124$

Hoegh-Guldberg O, Hinde R (1986) Studies on a nudibranch that contains zooxanthellae I. Photosynthesis, respiration and the translocation of newly fixed carbon by zoo- xanthellae in Pteraeolidia ianthina. Proc R Soc Lond B 228:493-509

Iglesias-Prieto R, Beltran V, LaJeunesse T, Reyes-Bonilla $\mathrm{H}$, Thome P (2004) Different algal symbionts explain the vertical distribution of dominant reef corals in the eastern Pacific. Proc R Soc Lond B, 271:1757-1763

Ishikura M, Hagiwara K, Takishita K, Haga M, MaruyamaT (2004) Isolation of new Symbiodinium strains from tridacnid giant clam (Tridacna crocea) and sea slug (Pteraeolidia ianthina) using culture medium containing giant clam tissue homogenate. Mar Biotechnol 6: 378-385

Johnson T, Terazaki M (2003) Species composition and depth distribution of chaetognaths in a Kuroshio warm-core ring and Oyashio water. J Plankton Res 25:1279-1289

Kempf S (1984) Symbiosis between the zooxanthella Symbiodinum (=Gymnodinium) microadriaticum and 4 species of nudibranchs. Biol Bull (Woods Hole) 166:110-126

Kempf S (1991) A primitive symbiosis between the aeolid nudibranch Berghia verrucicornis A. Costa 1867 and a zooxanthella. J Molluscan Stud 57:75-86

King D, Fraser V (2002) More reef fishes and nudibranchs: east and south coast of Southern Africa. Struik Publishers, Cape Town

LaJeunesse T, Trench R (2000) Biogeography of two species of Symbiodinium (Freudenthal) inhabiting the intertidal sea anemone Anthopleura elegantissima (Brandt). Biol Bull (Woods Hole) 199:126-134

LaJeunesse TC, Bhagooli R, Hidaka M, DeVantier L, Done T, Schmidt GW, Fitt WK, Hoegh-Guldberg O (2004) Closely related Symbiodinium spp. differ in relative dominance in coral reef host communities across environmental, latitudinal and biogeographic gradients. Mar Ecol Prog Ser 284: 147-161

Lewis C, Coffroth M (2004) The acquisition of exogenous algal symbionts by an octocoral after bleaching. Science 304 : 1490-1492

Little FL, van Oppen M, Willis B (2004) Flexibility in algal endosymbioses shapes growth in reef corals. Science 304: 1492-1495

Loh W, Loi T, Carter D, Hoegh-Guldberg O (2001) Genetic variability of the symbiotic dinoflagellates from the wide ranging coral species, Seriatopora hystrix and Acropora longicyathus, in the Indo-West Pacific. Mar Ecol Prog Ser 222:97-107

McFarland F, Muller-Parker G (1993) Photosynthesis and retention of zooxanthellae and zoochlorellae within aeolid nudibranch Aeolidia papillosa. Biol Bull (Woods Hole) 184: 223-229

Page RDM (1996) TREEVIEW: an application to display phylogenetic trees on personal computers. Comput Appl Biosci 12:357-358

Pochon X, LaJeunesse T, Pawlowski J (2004) Biogeographic partitioning and host specialization among foraminiferan dinoflagellate symbionts (Symbiodinium; Dinophyta). Mar Biol 146:17-27

Posada D, Crandall KA (1998) Modeltest: testing the model of DNA substitution. Bioinformatics 14:817-818

Rodriguez-Lanetty M, Loh W, Carter D, Hoegh-Guldberg O (2001) Latitudinal variability in symbiont specificity within the widespread coral Plesiastrea versipora. Mar Biol 138: $1175-1181$

Ronquist F, Huelsenbeck J (2003) MrBayes 3: Bayesian phylogenetic inference under mixed models. Bioinformatics 19: $1572-1574$

Rowan R (2004) Coral bleaching. Thermal adaptation in reef coral symbionts. Nature 430:742 
Rowan R, Knowlton N (1995) Intraspecific diversity and ecological zonation in coral-algal symbiosis. Proc Natl Acad Sci 92:2850-2853

Rowan R, Knowlton N, Baker A, Jara J (1997) Landscape ecology of algal symbionts creates variation in episodes of coral bleaching. Nature 388:265-269

Rudman W (1982) The taxonomy and biology of further aeolidacean and arminacean nudibranch molluscs with symbiotic zooxanthellae. Zool J Linn Soc 74:147-196

Rudman W (1991) Further studies on the taxonomy and biology of the octocoral-feeding genus Phyllodesmium Ehrenberg 1831 Nudibranchia Aeolidoidea. J Molluscan Stud 57: 167-204

Swofford DL (2002) PAUP*. Phylogenetic analysis using parsimony ( ${ }^{*}$ and other methods), 4.0 edn. Sinauer Associates, Sunderland, MA

Thompson JD, Higgins DG, Gibson TJ (1994) CLUSTAL W: Improving the sensitivity of progressive multiple sequence alignment through sequence weighting, position-specific gap penalties and weight matrix choice. Nucleic Acids Res 22:4673-4680

Toller W, Rowan R, Knowlton N (2001) Zooxanthellae of the Montastraea annularis species complex: patterns of distribution of four taxa of Symbiodinium on different reefs and across depths. Biol Bull (Woods Hole) 201: 348-364

Editorial responsibility: Charles Birkeland (Contributing Editor), Honolulu, Hawaii, USA
Trench RK (1997) Diversity of symbiotic dinoflagellates and the evolution of microalgal-invertebrate symbioses. Proc 8th Int Coral Reef Symp 2:1275-1286

van Oppen M, Palstra F, Piquet A, Miller D (2001) Patterns of coral-dinoflagellate associations in Acropora: significance of local availability and physiology of Symbiodinium strains and host-symbiont selectivity. Proc R Soc Lond B 268:1759-1767

Waegele H, Johnsen G (2001) Observations on the histology and photosynthetic performance if 'solar-powered' opistobranchs (Mollusca, Gastropoda, Opisthobranchia) containing symbiotic chloroplasts or zooxanthellae. Org Divers Evol 1:193-210

Waegele H, Vonnemann V, Waegele JW (2003) Towards a phylogeny of the Opistobranchia. In: Lydeard C, Lindberg D (eds) Molecular systematics and phylogeography of mollusks. Smithsonian Institution Press, Washington DC, p 185-228

Wilcox T (1998) Large-subunit ribosomal RNA systematics of symbiotic dinoflagellates: morphology does not recapitulate phylogeny. Mol Phylogenet Evol 10: 436-448

Wollscheid-Lengeling E, Boore J, Brown W, Waegele H (2001) The phylogeny of Nudibranchia (Opisthobranchia, Gastropoda, Mollusca) reconstructed by three molecular markers. Org Divers Evol 1:241-256

Submitted: February 23, 2005; Accepted: January 16, 2006 Proofs received from author(s): August 1, 2006 